\title{
The Importance of Taking a Process Perspective on the Use and Application of an Innovation Management Self-Assessment Audit
}

\author{
Helena Blackbright \\ helena.blackbright@mdh.se| School of Innovation, Design and Engineering, Mälardalen University, IDT, \\ Box 325, 63105 Eskilstuna, Sweden
}

\begin{abstract}
Prior research on innovation management self-assessment audits (IMSA) has a strong focus on the assessment situation, primarily on what to assess. However, several additional tasks are necessary to make purposeful use of an IMSA. This study analyzes the undertaking of an IMSA from a process perspective to better understand IMSA's utilization by looking at how people participate in the process and how the process is integrated in an organizational context. This study adopted an interactive research approach and collected data over a period of 27 months in 45 interviews, six workshops, and 10 meetings with 42 different participants from three companies. Results show a fragmented participation, and that the process was only partly integrated into the organizational context, making it arbitrarily dependent on individual actors. This demonstrates the need to understand challenges related to IMSA use to enable a process that is integrated in the structures intended to be improved.
\end{abstract}

Keywords. Assessment Process; Innovation Assessment; Innovation Audit; IMSA; IMSA-process; Process, Complexity; Discontinuity; Innovation; Innovation Management; Internal Assessor; Assessor.

Cite paper as: Blackbright, H., (2019). The Importance of Taking a Process Perspective on the Use and Application of an Innovation Management Self-Assessment Audit, Journal of Innovation Management, www.openjim.org, 7(4), 47-76. 


\section{Introduction}

Innovation management auditing and assessment have long been considered a vital part of good innovation management practices (Adams et al., 2006; Tidd and Bessant, 2013, Dewangan \& Godse, 2014), often providing scorecards and tools that give valuable opportunities to identify both strengths and weaknesses and also gaps between current and desired states (Coombs et al., 1998; Cormican \& O'Sullivan, 2004; Alegre et al., 2006; Tidd \& Bessant, 2013). However, despite giving a valuable indication about potential improvement areas (Chiesa et al., 1996; Radnor \& Noke, 2002; Bilsoslavo, 2005; Nilsson et al., 2010; Tidd \& Bessant, 2013), prior research has shown that assessors struggle with both making use of the assessment results (Karlsson, 2015) as well as preparing for and undertaking the assessments (e.g., Chiesa et al., 1996; Moultrie et al., 2007; Nilsson et al., 2010; Karlsson, 2015). It does not matter how relevant the assessment variables are or how precisely the gaps between current and desired states were identified; this does not in itself reveal how to actually close these gaps (Langley et al., 2013) in a way that leads to improvements in line with the intended purpose (Moynihan, 2009). To utilize a selfassessment with some sort of improvement purpose, more than just identifying the gap between current and desired states, is important (Samuelsson and Nilsson, 2002; Nilsson et al., 2010; Karlsson, 2015). It is critical to place the assessment indicators in a contextual setting where the assessment is considered from a holistic perspective (Samuelsson \& Nilsson, 2002) to understand why things emerge over time (Langly et al., 2013) and how to make purposeful use of the assessment (Kerssens-van Drongelen \& Bilderbeek, 1999; Panizzolo et al., 2010; Birchall et al., 2011; Karlsson 2015).

Although prior literature is often based on an understanding of innovation as a process, different studies often had a variance perspective on the process, and only few addressed the selfassessment itself as a process (e.g., Samuelsson and Nilsson, 2002; Hallgren, 2009; Nilsson et al., 2010; Karlsson, 2015). To build a better understanding of how to purposefully use (Moynihan, 2009) an innovation management self-assessment audit (IMSA) inspiration was drawn from scholars in processes and complex adaptive systems (Marion, 1999; Feldman \& Pentland, 2003; Ellström, 2010; Langley et al., 2013). In combination with insights from prior research on audits and self-assessment within the field of innovation management and quality management (Samuelsson \& Nilsson, 2002; Adams et al., 2006; Nilsson et al., 2010; Karlsson, 2015), this study's approach enables a focal shift from what to assess to instead focus on purposeful use of an IMSA within its organizational context.

In the undertaking of a process the activities interlink the participating actors to its context, more or less firmly binding them together over time, creating a bridge that allows information to be transferred between actors, enabling them to change its context, and also enabling the context to change the actors that populate the process (Marion, 1999). As most IMSAs have a direct or indirect improvement purpose, this purpose is in reality to change something in a way that makes the organization better (improved). Since organizational change in itself means that the structuring of the organization's social system is changed and maintained by its actors (Marion, 1999), the undertaking of an IMSA must therefore lead to both structural and behavioral changes to successfully fulfil its purpose. This motivates a study of both the people who are part of the process and their organizational context. With an overall objective to better understand the 
challenges of undertaking and utilizing an IMSA this perspective was applied to a longitudinal study of the implementation and application of an IMSA over a period of 27 months using qualitative data from 46 semi-structured interviews, seven workshops, and 10 meetings involving 39 participants from five assessment projects of three organizations. The following research questions were used to guide the research:

RQ 1: How are people made part of the IMSA process?

RQ 2: How is the IMSA process integrated in its organizational context?

Findings show that both the integration of the process in its organizational context and the inclusion of people in the process were done in an unstructured and informal way. The process thereby became arbitrarily dependent upon the understanding, ability, and will of key actors that possessed critical information, resources, and competence. This affected the process by fragmenting it in a way that created discontinuities in the information transfer that at its best made the process less effective and often constituted a hindrance to its undertaking and progression. Based on this, three major conclusions were drawn. First, the use of an IMSA comes with a meta-level challenge of understanding the challenges of undertaking and utilizing it. Second, to successfully utilize the IMSA it has to be related to the structures it is intended to change and the people that have an impact on these structures. Third, the continuation of the process must be given more consideration to allow information to accumulate and drive change.

\section{The process of undertaking a self-assessment}

With the goal of taking a process perspective on the use and application of an IMSA to better understand the related challenges this article continues with two sections that address the process of undertaking a self-assessment. First from the perspective of prior research which will then be followed by a section that provides a broader theoretical framework.

\subsection{Prior research}

Measuring and assessing innovation is considered a vital part of good innovation management (Adams et al., 2006), and there is abundant research on assessments and measurements of different aspects of the innovation process and organizational innovativeness. Although an increasing number of papers address the use of innovation measurements and assessments (Dobni and Klassen, 2018; Janssen et al., 2011), only few focus explicitly on the requirements of the people who participated in the process (Karlsson, 2015), and on how to undertake and utilize the information extracted from the assessments (Birchall et al., 2011; Adams et al., 2006).

Although prior studies on innovation management measurement and assessment often focused on what to assess (e.g. Dobni, 2008), several directly or indirectly addressed issues related to the undertaking and utilization of assessments. While these studies did not directly study the undertaking or the utilization, they often provided valuable input that can be used to place the assessment in a wider use-context. A wider use-context is often represented by the existence of direct and indirect descriptions of issues, tasks, activities, and qualifications that have been 
shown to enable or disable a purposeful use of an assessment. Since these areas are often outside the direct research scope of these studies, these aspects are seldom directly addressed, but they still confirm that making use of a self-assessment requires more than simply undertaking the selfassessment of one's current state (Samuelsson and Nilsson, 2002; Nilsson et al., 2010; Karlsson, 2015).

The description of what can be considered a use-context differs between papers. Some described preparatory issues and the tasks that forego the self-assessment in itself, for example, activities performed to raise awareness about the assessed area before the assessment is undertaken (Nilsson et al., 2010). Others are related to qualifications that affect the ability to undertake the selfassessment, for example, senior managers being too far from the assessed area to be the best auditors (Chiesa et al., 1996) or a lack of understanding of the metrics used (Janssen et al., 2011). Others mentioned the contextualization of metrics (Chiesa et al., 1996) and still others described issues and tasks that were related to the utilization of the self-assessment results and the work of transforming them into improvements and changes. The most common of the explicit suggestions is that the assessment results can be used as an input to guide decision making (Birchall et al., 2011) and act as a base for transforming activities that could lead to improvements (Radnor and Noke, 2002; Cormican and O'Sullivan, 2004; Björkdahl and Börjesson, 2012). Some were directly mentioned as something that could be done, others described situations where it could be understood that specific tasks have been undertaken or specific competencies have been part of the undertaking, and others illustrated problems that indirectly described requirements or activities. However, it is unusual to find papers within the innovation management field that focus directly on the undertaking and utilization of the assessment.

Prior studies within the quality management field more frequently address the undertaking of the assessment and the people taking part in the assessment more so than studies within the field of innovation management. The undertaking of the assessment itself, not only the assessment results, has more often been treated as an important part of the improvement groundwork. However, research within quality management is also criticized for not taking a holistic perspective on self-assessments (Samuelsson \& Nilsson, 2002), which risks isolating the indicators from the characteristics of the organization against which it needs to be interpreted (Carayannis and Provance, 2008).

A qualitative study by Svensson and Klefsjö (2006) from the field of quality management provided findings that highlighted the issues often addressed indirectly in innovation management research. Personnel that participated in a self-assessment felt that they received too little self-assessment training, and perceived the terminology to be abstract and the questions difficult to understand. The same study further showed that participants did not understand the purpose (for whom it was undertaken and why) and were unable to see how they would benefit from the process. Also, managers underestimated the resources required to undertake the self-assessment. Several of the participants experienced that insufficient time and support were provided to undertake the assessment process (Svensson and Klefsjö, 2006).

Both Svensson and Klefsjö (2006) and Samuelsson and Nilsson (2002) described the self-assessment as a process in a way that reminds much of the work of Hallgren (2009), Nilsson et al. (2010), and Karlsson (2015). All of them approaching the assessment use as a process in a way that 
incorporates much of the issues that have often been addressed, directly or indirectly, in prior innovation management studies but outside primary focus. Karlsson (2015), as well as Samuelsson and Nilsson (2002), directly addressed the assessment process in their research. When merging these two studies into one model (Fig. 1) they show great similarities, both describing a process that covers the wider scope of tasks, activities, and participants that is often indirectly addressed in prior innovation management research. The process involves both preparing tasks that precede the assessment and tasks should follow it (Fig. 1). Karlsson (2015) focused primarily on the structural division of the process in relation to the task of self-assessing one's current state. Described as a three-staged process consisting of a pre-assessment phase, where all the assessment preparations are undertaken; an assessment-phase, where an assessment of the current state is undertaken; and finally, a post-assessment-phase, where all the activities required to turn assessment results into activities that lead toward the assessment purpose are conducted. Samuelsson and Nilsson (2002) described a very similar process structure and did unlike Karlsson (2015) also provide a more detailed description of the process content (Samuelsson \& Nilsson, 2002). In comparison, Karlsson (2015) addressed the process from three perspectives: what to assess, who to participate, and how to undertake the assessment.

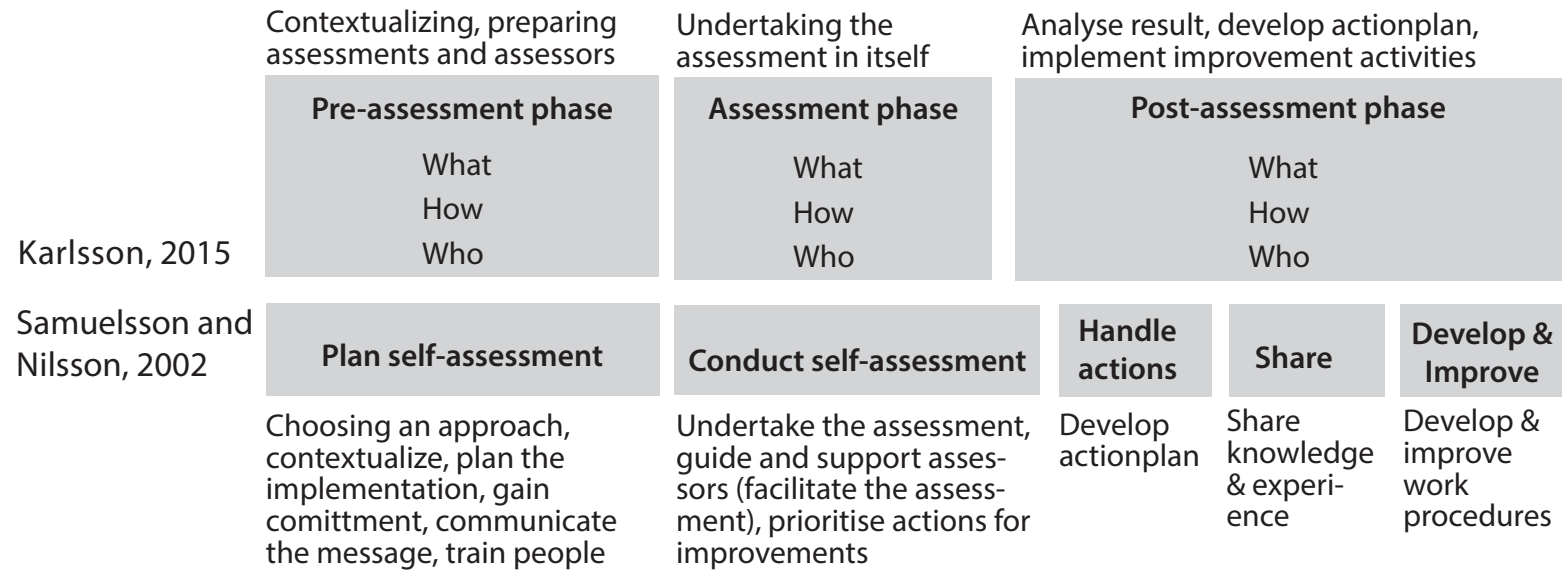

Fig. 1. This shows a comparison between the self-assessment processes as described by Samuelsson \& Nilsson (2002) and Karlsson (2015).

The primary focus of prior innovation management research, when compared to Fig. 1, is on the assessment phase where it has its main representation in the what dimension (e.g., Chiesa et al. 1996; Alegre et al., 2006; Moultrie et al., 2007; Björkdahl and Börjesson, 2012; Croplay et al., 2013). However, we can also see that issues that have been addressed but not considered the primary focus of prior innovation management research match well with the pre- and postassessment phases (e.g., Chiesa et al., 1996; Cormican \& O’Sullivan, 2004; Nilsson et al., 2010; Dobni and Klassen, 2018), and that these are also to a large extent related to the dimensions of how and who. 


\subsection{Theoretical framework}

When addressing an IMSA as a process, the focus is on the interaction and informational transaction that interlink actors, activities, and tasks to each other as well as to their organizational context, giving both the structures and the actors an explanatory power (Langley et al., 2013) as they together bridge time in a way that allows information to be transferred within the system and eventually enables actors that populate the process to change its context and vice versa (Marion, 1999). On the one hand, this results in a complexity that prevents the development of the process to be fully predicted in a deterministic way but on the other hand, this enables the emergence of results greater than the sum of its single parts. (Ibid)

\subsubsection{Shifting focus from what to how.}

A process in itself can be recognized as a pattern of activities that is continuously changing and developing over time as undertaken by the actors participating in the assessment process, recognizable because it has certain delimitations towards its outer world but also interdependently interlinked in its contextual setting. As soon as the IMSA is described as a process it must come with the recognition of complexity and contextual setting as well as time, interaction, and agency as these are all important elements that impact the continuation of the process (Prigogine, 1997; Marion, 1999; Langley et al., 2013).

Addressing the IMSA as a work process that recognizes time and context helps break the analytical isolation (Carayannis and Provance, 2008) and enables a better understanding of how and why the process emerges and develops the way it does (Langley et al., 2013). It also allows us to address the process from two structural sides, a formalized and a performative side.

The formal structure is the description of the process as it is intended to be undertaken (e.g., as described by the audit). The other side is the practical, actual undertaking of the process, how it is actually done (Ellström, 2010; Feldman \& Pentland, 2003).

Formalization can be done in several ways, both explicitly and tacitly, through the normalization of operational procedures that codify in a specific context the taken-for-granted norms and tacit elements in procedural knowledge. However, formalization may also be achieved through explicit and formal descriptions of how the process is intended to be undertaken in terms of standards or work descriptions (Ellström, 2010). The formalized structures provided by most IMSAs concern only a limited part of the process suggested by Karlsson (2015) and Samuelsson \& Nilsson (2002) (the assessment-phase). Although the formalized side of a work process is often said to be overestimated in terms of importance and impact (Ellström, 2010), the provided structure makes the process less abstract and easier for the assessors to use (Anderson \& Krathwohl, 2001; Panizzolo et al., 2010). The formalized side makes it easier for actors to take part in a process even when it is not fully understood (Feldman \& Pentland, 2003). When only a small part of an IMSA process is formally codified, less support is provided to the actors involved in the assessment process. Either large parts of the process will have to be undertaken under conditions where no formal codification is provided or formalization of the process has to be made part of the IMSA process as a task in itself. Both scenarios require a certain level of experience and knowledge from those who will be part of such a process (Anderson \& Krathwohl, 2001).

However, no matter how well-described the formalized side of the process (or a part of the process) 
is, it can never be described in such detail that everyone perceives it and undertakes it in exactly the same way. Every action undertaken is impacted, and to some extent formed, by both the individuals' own structures and the surrounding structures (Backström, 2018). Therefore, besides the formally described process, there is always an actual undertaking, a performance of specific activities performed by specific actors at specific times and places. This is the performative (tacit) side of the process (Feldman and Pentland, 2003; Ellström, 2010).

\subsubsection{Structurally formed interaction and complexity.}

As with any process where a large number of interactions between interdependent actors and factors $^{1}$ (processes) take place, complexity is part of the IMSA process as well. The interdependent actors and factors form a system together in which the interaction between them constitutes the very core of the process (Marion, 1999). At the heart of the process, both driving its progression and causing its complexity, is the interaction. Unlike action that can have a one-way causal effect, interaction is in itself defined as having a mutual effect on its interacting parties caused by the information transaction that regulates the behavior of the involved (Prigogine, 1997). Not necessarily through verbal communication but also by saying nothing, information that has an impact on the social structure is transferred when observing how colleagues work, or through facial expressions, clothing, and a lot of other things (Berger \& Luckman, 1979). This has a mutual impact on them as individual actors and on them as a group, affecting their behavior even if only temporarily. The actions of every social group, consisting of two or more actors, are impacted and formed by their surrounding structures that affect the operationalization of an IMSA. Both external and internal structures affect every activity that is undertaken throughout the assessment process with the external being beyond the ability of actors to change, while the internal are created and recreated by the activities undertaken by the group (Fig. 2).

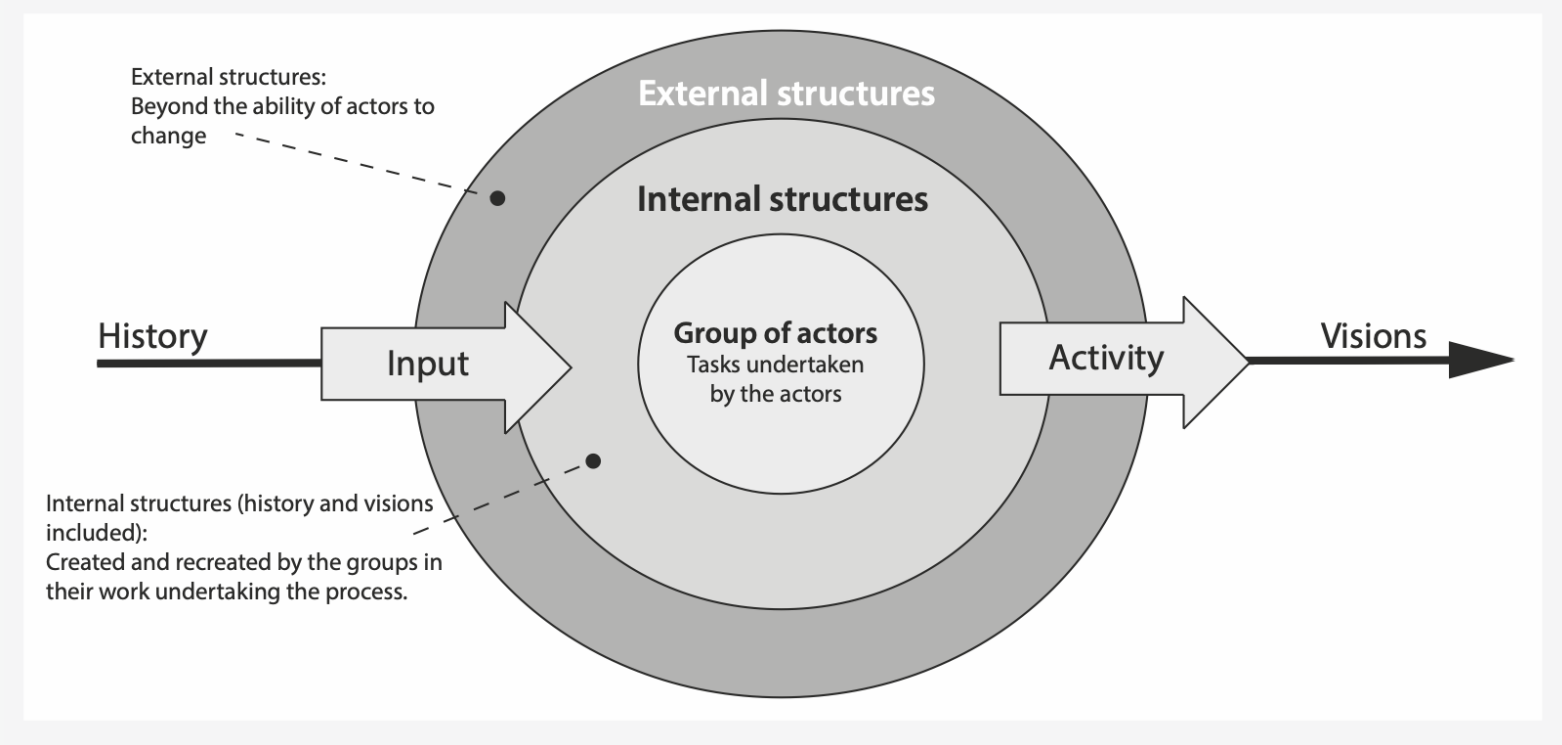

$1 \quad$ Any "factor" of a complex and dynamic system as a process is actually a reification of a process, constituted "by varying and fluctuating activities" (Langely et al., 2013) that are interdependently connected to other processes.However, for readability reasons the term "factors" will be used here. 
Fig. 2. Visualization of structures impacting the assessment groups (inspired by "Fig 5.2 Organisation ur ett perspektiv av social interaktion [Organisation from the perspective of social interaction]" from Backström, Döös \& Wilhelmson 2006).

The process in itself is an enactment of these internal and external group structures as well as structures of the individual actor. Together, these three types of structures constitute the prerequisites for all interactions between different actors throughout the assessment process, forming the assessment process through their impact on the individual actors and on their social interactions. As a result, all interactions between different actors lead to either a modification or a reinforcement of individual prerequisites and internal structures (Fig. 3), leading us to a circular causality where interactions are formed by structures at the same time as these structures are reinforced or modified by the interactions undertaken (Marion, 1999).

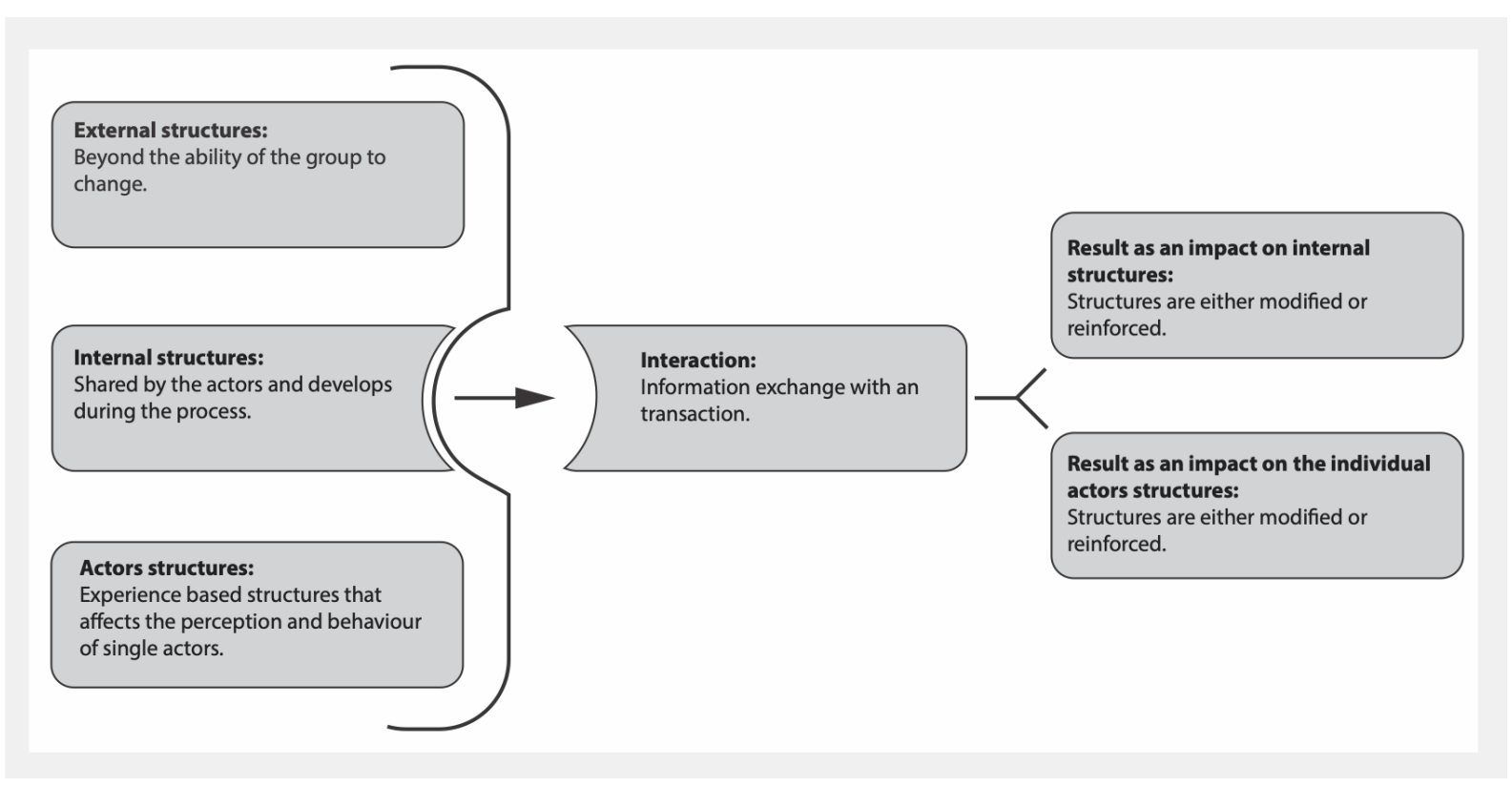

Fig. 3. The GroPro model from Backström, T. (2018): "How to understand and facilitate creative group processes - The GroPro model."

Even though the stated overall purpose of different assessment tools varies, prior research often contain formulations that give them a direct or indirect improvement purpose. These formulations state that the use of the tool should, or could, lead to an improvement of the assessed area by, for example, bringing attention to "what needs to be improved" (Yang et al., 2001), or suggesting that it "... would be a considerable help in improving actions during the innovation process" (Cropley et al., 2013), or "... can be used to manage and optimize the innovation process internally" (Carayannis and Provance, 2008). Purposes that require the undertaking of an IMSA lead to a structural modification and thereby indirectly stress the need to acknowledge the structures that constitute the contextual setting within which these pre-assessment and post-assessment activities (Karlsson, 2015; Samuelsson \& Nilsson, 2002) should be undertaken, performed, and formed under the influence of structures that are both within and beyond the actor's ability to 
develop through the process, enabling or disabling the required information transfer to take place (Marion, 1999).

Any work process, including the assessment process, is in itself constituted by an interwoven combination of a performative side and a formalized side that co-exist in a continuous change, developing over time through the information transfer that comes with the activities that are and are not undertaken by the actors involved in the process. Over time, this pattern of activities and continuous change bind what is done, to how it is done, and why in that specific contextual setting in time, allowing us to give the activities undertaken (or not undertaken) an explanation value, helping us to build understanding and explain how and why a process develops the way it does (Langley et al., 2013). The process perspective provides us with a possibility to add a timely context to prior IMSA research by expanding the reasoning of, for instance, Karlsson (2015), Panizzolo et al. (2010), and Biazzo \& Bernardi (2003) by using Ellström's (2010) and Feldman \& Pentland's (2003) research on routines and work processes.

\section{Method}

Taking a process perspective on an organization (or assessing units) undertaking an IMSA comes with some interesting methodological opportunities and requirements. As a dynamic process, such as the undertaking of an IMSA, is an embedded part of a complex adaptive social system, the process cannot be understood as a set of dependent variables (Maxwell, 2013). Instead, the process can be seen as a "sequence of events or activities that describes how things change over time" (Van De Ven, 1992), this forms a process with an ontological viewpoint that "tends to associate with a dynamic social constructivist view" (Langley et al., 2013). We have to move closer to the actual behavior of people (Pettigrew et al, 2001) as it illustrates the "ongoing interactions among different individuals, between individuals and organizations, and between multiple levels across organizations and contexts permeate and orient change processes" (Langley et al., 2013). The recognition of the complexity and contextual setting, as well as time, interaction, and agency, become important elements that affect the development of the process (Prigogine, 1997; Marion, 1999; Langley et al., 2013). Therefore, choosing case companies where a close relation could be established and where rich qualitative data could be accessed through a longitudinal study (Yin, 2009) that gave an opportunity to be closer to the actual behavior of people (Pettigrew et al., 2001) was prioritized (Maxwell, 2013). Data came from a period of 27 months within a research project that stretched over 36 months that explored the use of an IMSA as a means to increase innovativeness. An interactive research approach (Svensson et al. 2007; Ohlsson \& Johansson 2010) was adopted and conducted in close collaboration with three companies referred to as A, B, and $\mathrm{C}$ below. All participants were situated in a context of everyday work structures (Ellström 2010, Feldman \& Pentland 2003). Case selection, empirical data collection, and analysis of the data used will be described further below. 
Table 1. Description of the case companies

\begin{tabular}{|c|c|c|c|c|}
\hline Company & Description & Industry & cases & No of employees \\
\hline A & $\begin{array}{l}\text { Multinational organization active in more } \\
\text { than } 100 \text { countries }\end{array}$ & Hi-Tech engineering & $\begin{array}{l}\text { One assessment group, within division } \\
\text { located in central Sweden. }\end{array}$ & $\begin{array}{l}\text { Globally }>140000 \\
\text { Division }<500\end{array}$ \\
\hline B & $\begin{array}{l}\text { Multinational organization active in } 28 \\
\text { countries }\end{array}$ & Hi-Tech engineering & $\begin{array}{l}\text { Two assessment groups, within division } \\
\text { located in central Sweden. }\end{array}$ & $\begin{array}{l}\text { Globally }>60000 \\
\text { Division }<500\end{array}$ \\
\hline C & $\begin{array}{l}\text { Nordic organization active in Sweden, } \\
\text { Denmark and Norway }\end{array}$ & Technical IT-Consultants & $\begin{array}{l}\text { Two assessment groups, within regional } \\
\text { office located in central Sweden. }\end{array}$ & $\begin{array}{l}\text { Nordic organization } 600 \\
\text { Regional office }<400\end{array}$ \\
\hline
\end{tabular}

\subsection{Case selection and company's motivation to participate}

Three companies, here referred to as company A, B and C have been part of the study (table 1)

The three companies were deliberately selected (Maxwell, 2013) for two reasons:

The first reason was that they were facing challenges caused by shifts in technology and new business models. This created high levels of uncertainty and heavy pressure to re-innovate themselves in different ways as they were struggling to keep leading positions and increase revenue. Company A and B were both divisions within large global organizations with tens of thousands of employees. Both were global leaders under heavy pressure when the project was initiated. Company A faced a situation where new technology was assumed to do their core competence (used to be their sign of quality), rendering it almost unnecessary in the immediate future. Company B was struggling to keep up with actors who could offer prices and conditions they could not match, even though they were convinced that their products performed better and were more cost effective in the long run. Company C, a smaller consultancy-based organization that was very successful at the Nordic market, faced a slightly different situation, not threatened by technological development but an increased structural separation between purchaser and customer. Purchasers were experienced to have a strong focus on short-term costs in the procurement situation, caused by a lack of understanding of real needs. As a consequence, they were facing declining opportunities both to build revenue and create customer value.

Second, selection was done because there was a well-established relationship with the participating companies. Some of the company representatives that were involved had collaborated on a regular basis over several years with the researchers as well as with each other outside the research project. This was considered an important design decision as it was believed to facilitate a close interaction with the researchers as well as between companies during the research project (Maxwell, 2013). These conditions were considered important to enable a qualitative research design that required accessibility, openness, and trust between both organizations, the participants and researchers.

Commitment to participate in the research project was developed through several discussions with senior managers and middle managers in all three companies, discussing motivation to participate, expected outcomes, and requirements. The decision to participate was taken by senior managers on a national level and the middle managers who would in practice lead the assessment project. All three companies entered the project with a shared purpose in undertaking 
a continuous assessment of innovative climate to involve more people in innovation. The objective was to find new ways of creating value to maintain their leading positions.

\subsection{The IMSA used}

An existing web-based IMSA focused on ten dimensions of organizational climate for innovation was used in existing groups of 10 to 20 participants. Company A participated with one group, company $\mathrm{B}$ and $\mathrm{C}$ with two groups each. A link to the assessment form was automatically mailed once a week to the assessors. Assessments were undertaken individually by estimating how well ten predefined statements (inspired by the research of Ekvall from 1996) described their perception of the past week on an ungraded scale that spanned from "not true " to "absolutely true". After each assessment auto-generated feedback with information on the last assessment, comparisons with prior assessments and trend-charts were provided together with brief information on how the assessed items related to innovation. The manager in each group was given the role of a feedback provider who was given feedback on the entire assessment group while the rest of the assessors were provided feedback only on their individual assessments. The purpose was to give the group an incentive to go through the group-level feedback together. Feedback providers were encouraged to regularly integrate discussion, reflection, and analysis of the results in established routines and meetings. Two of the feedback providers in company A had previously participated as feedback providers in a pilot study where the IMSA was used.

\subsection{Collection and analysis of the empirical material}

The empirical material used in this study came from 46 interviews, seven workshops, one observation, and 10 meetings with the three participating companies over 27 months. Five assessment projects were analyzed in which the focus was on how people were made part of the process and how the process was integrated in its organizational context, trying to see how this affected the undertaking of the process and its continuation. Figure 4 gives an overview of the empirical material used in the article. 


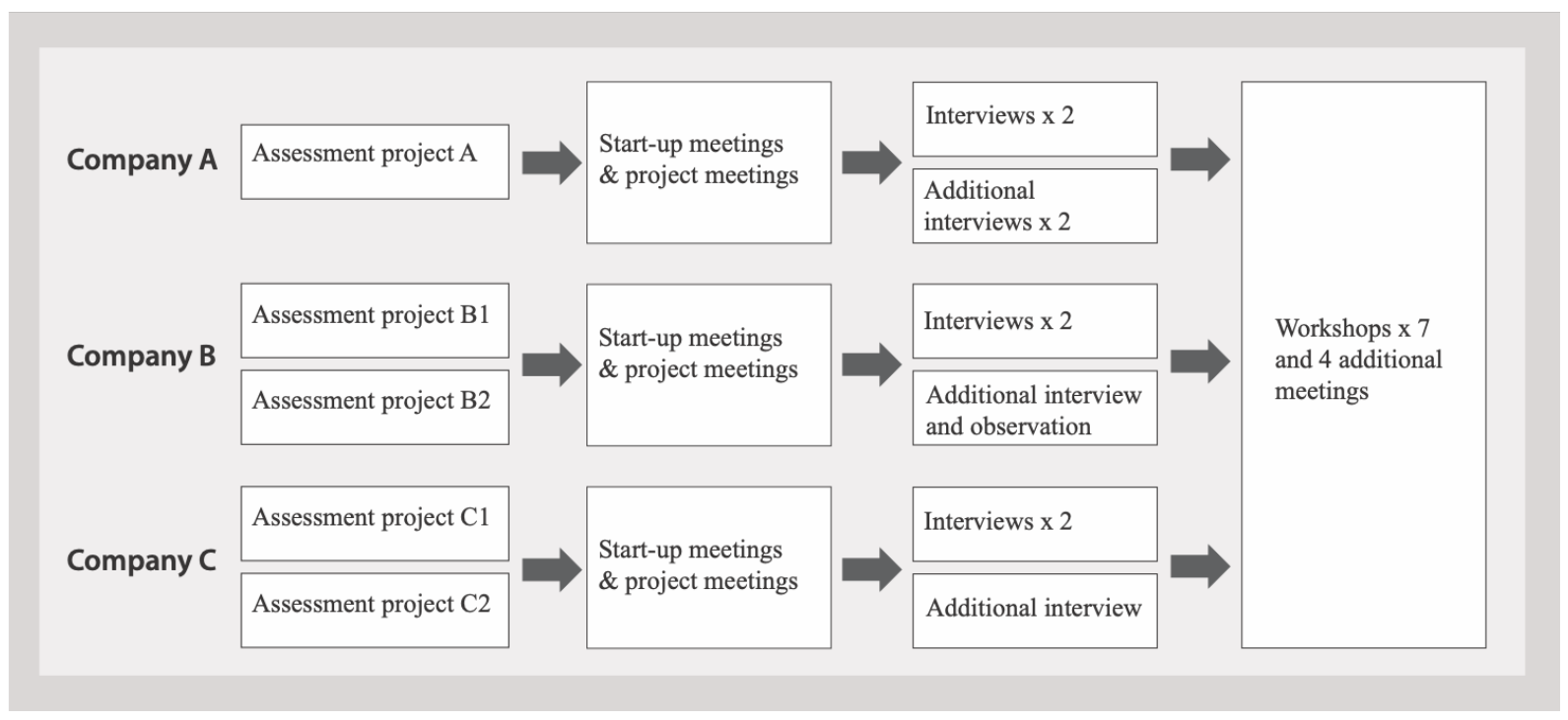

Fig. 4. Overview of the empirical material used in the article

Workshops and meetings. Both workshops and interviews gave access to rich data (Maxwell, 2013) that provided information from both the perspectives of single individuals and each of the organizations that hosted the assessment groups that were not as accessible in the interviews.

The feedback provider and one assessor from each assessment group were invited to the workshops that lasted for four hours, and consisted of three parts. The first part was used for an interactive focus group discussion (Merriam \& Tisdell, 2016). These provided an opportunity for the participants to reflect and share experiences about progression, use, attitude, and important contextual factors and also gain support from each other and from the researchers. This was then followed by a discussion and undertaking of practical exercises related to their own organizational context. Finally, each workshop was summarized in a forward-oriented discussion where the participants reflected on the theme of the workshop and decided if and how they wanted to work specifically with the theme.

Short reflective field notes were taken during the workshops (Merriam \& Tisdell, 2016) and all workshops were thereto audio-recorded in their entirety.

The ten meetings were held with both individual participants and groups of participants. Initial and start-up meetings were planned and initiated by the researchers, addressing pre-assessment issues related to goal-setting, selection of assessors, expectations, and other similar matters. Remaining meetings were initiated by participants and were all related to the undertaking of the assessment process. Meetings lasted between 30 minutes and two hours and were audio-recorded. Written documentation on goals and expectations was used in the start-up meeting.

\subsubsection{Interviews and observation.}

Forty-six semi-structured interviews were conducted (Saunders et al., 2012) with 26 different participants, 20 of which were undertaken initially in the project and another 18 after 18 months. The interviews covered open-ended questions (Peterson, 2000) concerning the participants' con- 
ceptions about innovation and how they were working with innovation on a daily basis, as well as more specific questions concerning the use and impact of the IMSA. The interviews lasted from thirty to ninety minutes.

Four additional interviews were conducted when circumstances provided especially interesting situations that offered a deeper understanding of the situation. As an example, a second interview was conducted with one of the feedback providers in company $\mathrm{C}$ when he left the organization.

One interview with a feedback provider from company B was foregone by an observation of a feedback meeting where the feedback provider shared assessment results with the assessment group with the researchers participating as observers (Merriam \& Tisdell, 2016). An observation guide was used to collect data and was then used as basis for a following dialogic interview (Rossman \& Rallis, 1998) with the feedback provider.

All interviews were audio recorded.

\subsubsection{Managing and analyzing the empirical material.}

A first analysis (Fig. 5) was done while listening to the audio recordings from workshops, meetings, and interviews using written memos for a first open coding (Merriam \& Tisdell, 2016). Based on this a selection of recordings was summarized in text and transcribed in whole or in part.

Thereafter, a second analysis was done focusing on how people were made part of the assessment, how it was integrated in its organizational context, and how that affected the undertaking of the process (Fig. 5). 


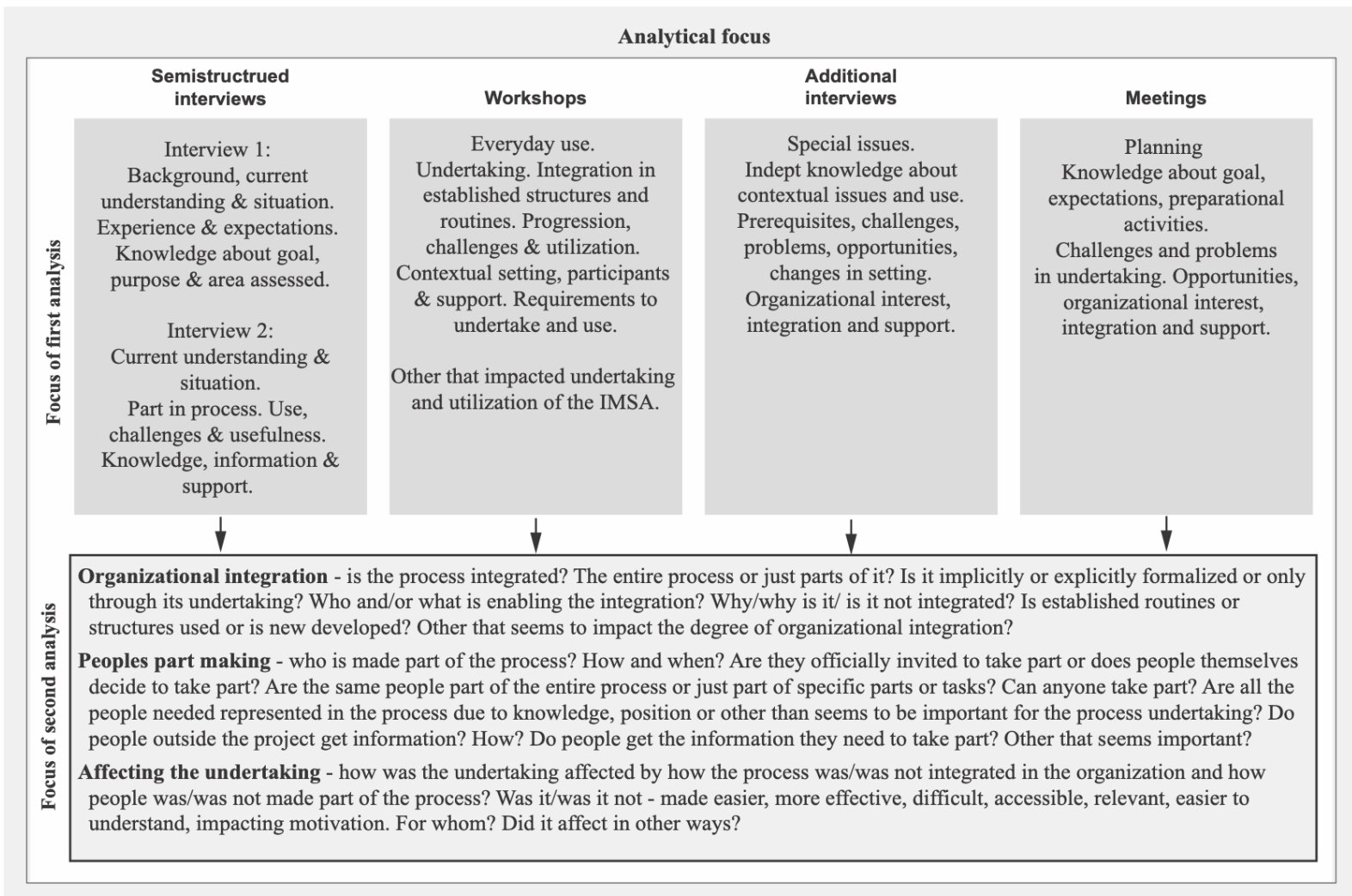

Fig. 5. The analytical focus of interviews, workshops and meetings.

To validate the results and analysis, these were presented to the participating companies in two workshops where they were given the opportunity to provide input to and reflection on the ongoing analysis.

\section{Discontinuities breaking the progression}

In the search for better understanding of the challenges related to the undertaking and application of an IMSA a process perspective was used when researching five assessment processes, focusing on how people were made part of the IMSA process, and how the IMSA process was integrated in its organizational context.

A major part of the assessment process in terms of content, design, and undertaking (e.g., participants, tasks, activities, support, and organizational utilization) was provided undefined and thereby neither formalized nor structured. How people were made part of the process and how it was integrated in its organizational context was to a large extent closely related to the participants' ability to define and structure the process. The undertaking of these activities was often largely intertwined that they were sometimes hard to separate from each other.

Handling unbalanced and discontinuous interlinkages between actors, tasks, and support constituted the major integrating and interacting challenges. All together this gave a discontinuous 
IMSA process that was highly interdependent, and as a consequence, dependent upon the competence and will of individual actors.

\subsection{Organizational integration}

None of the assessment processes was in its entirety explicitly or implicitly formalized and integrated as part of its organizational context and neither was any of the assessment processes organizationally integrated in its entirety through its undertaking. Even though the assessment process in project A was successfully undertaken in its entirety, only parts of it could be considered integrated in the organizational context as the major part of the process was unformalized and undertaken by one single individual. When that individual no longer found the process meaningful, no one else had enough information to maintain its continued undertaking and thus, the process stopped.

The major part of the assessment process in terms of content, design, undertaking, and utilization was provided undefined and thereby unformalized. As a consequence, organizational integration, to a large extent, became related to the definition and formalization of the tasks and activities necessary to undertake as the process in its provided shape seemed to be difficult to grasp, discuss, and relate to existing structures, routines, and positions. Defining the process content was a highly intertwined part of the organizational integration.

As the definition of tasks was shown to play such an important role for the integration, this section starts with a summary of the identified tasks and how the project participants managed to undertake them.

\subsubsection{Defining, undertaking and integrating.}

When analyzing the assessment projects, 18 areas of assessment tasks were identified as important to the project's quality and progression (Table 3). Not all tasks were part of all projects but proved to be important as they were undertaken; or caused problems or hindered the process as they were not undertaken. Some were chronologically dependent on other tasks (e.g., assessments needed to be undertaken before their result could be analyzed), others were not (e.g., assessments could be undertaken before the assessment purpose was formulated). Some could be mapped within an assessment phase while others had a role throughout the entire project (e.g., enabling interaction).

The tasks that were provided explicitly formalized and automatically undertaken by the IMSA (distribution, compilation, and dissemination) were integrated in the everyday work of those who participated as assessors and feedback providers. The tasks that needed to be defined by the participants in the assessment projects did, however, show to be a challenge. Three out of five assessment projects (B2, C1, and $\mathrm{C} 2$ ) did not undertake or manage to integrate (in either the process's internal organization or the wider organizational context) any of the activities that was not initiated by the researchers or provided explicitly formalized.

Three of the five projects (B1, C1, and C2) identified and addressed several tasks that were never managed, formalized, or undertaken. In B1 the feedback provider wanted to integrate the assessments in a new work group but needed support from senior management to enable 
Table 2. Identified assessment tasks, clustered in relation to task content and phase undertaken (Tasks in italics have caused problems in three or more of the assessment projects.)

\begin{tabular}{|c|c|c|}
\hline \multicolumn{3}{|c|}{ Assessment tasks } \\
\hline Pre-assessment phase & Assessment phase & Post-assessment phase \\
\hline $\begin{array}{l}\text { Engaging in the assessment (Initiated by } \\
\text { researchers) } \\
\text { Purpose formulation (No clear purpose } \\
\text { shared within any project) } \\
\text { Assigning participants (Initiated by } \\
\text { researchers, undertaken in all projects) } \\
\text { Goal formulation (Initiated and formalized by } \\
\text { researchers, undertaken in all projects) } \\
\text { Contextualization of tool or process (Initiated } \\
\text { and undertaken in project A, initiated in } \\
\text { project } \mathrm{C} 1 \text { and } \mathrm{C} 2 \text { but not undertaken) }\end{array}$ & $\begin{array}{l}\text { Distribution of assessment form ( Formalized } \\
\text { and partly undertaken by IMSA) } \\
\text { Undertaking the assessment (Formalized by } \\
\text { IMSA, undertaken in project A, B1, B2, C1 } \\
\text { and C2) }\end{array}$ & $\begin{array}{l}\text { Compile results (Formalized and undertaken } \\
\text { by IMSA) } \\
\text { Dissemination of individual results (Formalized } \\
\text { and undertaken by IMSA) } \\
\text { Dissemination of group results (partly formalized } \\
\text { and undertaken by IMSA, for a delimited time } \\
\text { formalized and undertaken in project A and B1) } \\
\text { Result analysis (for a delimited time formalized } \\
\text { and undertaken in project A and B1) } \\
\text { Formulate improvement activities (Formulation } \\
\text { of activities undertaken in project A) } \\
\text { Undertake improvement activities (To some } \\
\text { extent undertaken in project A) }\end{array}$ \\
\hline \multicolumn{3}{|c|}{$\begin{array}{l}\text { Defining and structuring tasks that were not provided defined and structured (Major part of the tasks defined, structured and undertaken by single key } \\
\text { actors in project A, single tasks defined, structured and undertaken in project B1,single tasks defined but not structured and undertaken in project } \\
\mathrm{C} 1 \text { and C2 ) }\end{array}$} \\
\hline $\begin{array}{l}\text { Providing required recourses (To a delimited } \\
\text { Goal dissemination (Goal dissemination not } \mathrm{u} \\
\text { Enable interaction (To a delimited extent forn } \\
\text { Provide required support (To some delimited }\end{array}$ & $\begin{array}{l}\text { t undertaken in project } \mathrm{A} \text { and } \mathrm{B} 1 \text { ) } \\
\text { taken in any project) } \\
\text { ed and enabled in project } \mathrm{A} \text { and } \mathrm{B} 1 \text { ) } \\
\text { t provided in project } \mathrm{A} \text { and } \mathrm{B} 1 \text { ) }\end{array}$ & \\
\hline
\end{tabular}

\section{ISSN 2183-0606}

http://www.open-jim.org

http://creativecommons.org/licenses/by/3.0 
this. The assessment group in B1 identified several improvement areas in their analysis of the assessment results but needed senior management's support to proceed with the formulation and undertaking of improvement activities. Feedback providers in $\mathrm{C} 1$ and $\mathrm{C} 2$ also identified the need for senior managers' support and provision of resources (i.e., time, similar to the situation in B1). Support was not provided in any of these situations and the process stopped. In $\mathrm{C} 1$ and $\mathrm{C} 2$ feedback providers, together with senior management, identified the need to contextualize but did not manage to do so. $\mathrm{C} 1$ and $\mathrm{C} 2$ had the will and ambition to establish a routine to share, discuss, and analyze the group level results with the assessment group but never managed to figure out how to actually do so.

\subsubsection{Successfully undertaken tasks.}

Two of the projects (A and B1) managed to define, formalize, and undertake the result dissemination for discussion and analysis in established meeting routines. For a time, these tasks were successfully integrated in the organizational context of those who participated as assessors and feedback providers. Both these meeting routines ceased as a result of organizational changes. In B1 the feedback provider managed to create a new meeting routine where the assessment group continued to discuss and analyze the assessment results. This ceased after a while as the group was unable to integrate with the outside organization to access support and authority required to formulate and undertake improvement activities.

Lack in interaction between different participants caused problems at several points throughout the project. For instance, the feedback providers at both company $\mathrm{B}$ and $\mathrm{C}$ in several occasions were unable to access the required support in terms of both competence and authority. This was particularly evident during the post-assessment phase, where support from senior managers was needed but not provided. At company B, the feedback provider struggled with the task of turning analytics into actions. He claimed that he lacked the required authority linked to the IMSA and stressed the need for a stronger organizational commitment and support.

"There is a lack of managerial commitment," (Feedback provider, project B1).

In a very similar way both feedback providers in projects B2 and C2 experienced a problem in accessing the required support from senior managers initially due to low engagement and later due to a lack of competence where senior managers could not provide the support needed. This caused repeated disruptions in the assessment work.

"If our organization had been interested and been driving this, it would have become a more natural part of our business...," (Feedback provider, project C2).

In project $\mathrm{A}$ the feedback provider continued to initiate an ongoing analysis of the assessment results, sometimes involving other actors but mainly on his own. However, the planning and undertaking of the activities in both projects A and B1 were primarily related to the work of single individuals and could not be considered formalized or integrated in the organizational context other than in limited parts. In project $\mathrm{A}$ the feedback provider used internal communication channels (internal screens) to publicize written information about the ongoing project to the entire organization. 


\subsection{Depending on single individuals}

Overall the undertaking of the assessment process was arbitrarily dependent upon the single individuals taking part in the process. The integration depended on a combination of his or her engagement, competence, and position within the organization, how he/she understood his/her role in the process, the area assessed, and how important it was considered; and also how the content of the assessment process was understood. This, in combination with their role within the organization, greatly affected their real and experienced need of support and their ability to access support through their established relations and communication channels. Together, these factors had a major impact on how the individuals strived to and were able to integrate the process content within its organizational context.

Two feedback providers, who had prior experience of using the IMSA and of the area assessed, managed better than the others in defining and undertaking the tasks that were not directly described and supported by the IMSA. They also acted as assessment champions both internally in their organization (A) and in interaction with participants from the other projects. They defined and structured the tasks in project A. However, the project in itself could only be considered as partly integrated in its organizational context as it was not formalized and highly bound to them as individuals. They served as the link between single tasks and participants, becoming key actors where the more senior of them "owned" the process as a whole, binding different tasks together and linking them to a purpose. If they would have left the process it is doubtful if anyone else would have had access to information enough to maintain the process. Project A was the only project where all three assessment phases were successfully undertaken.

The feedback provider says he believes that they being champions has been "crucial." I believe he said "that the individual's personal drive and conviction is essential when trying to elicit the development of other individuals' personal drive and conviction. ... one individual's drive can expand by being absorbed by other individuals, and I think we have succeeded in that because it is no longer just me; now there are other individuals who have adopted this and continue to drive it," (Feedback provider project A).

No single individual in the other projects possessed the required combination of knowledge, position, and engagement to single-handedly take a holistic lead on the project throughout the entire process. No process champion who "owned" the entire process could be identified in any of the other projects and neither was the process in any of the projects formalized or integrated in the organizational context in such a way that the project was successfully given an organizationally-shared "ownership" that could provide it with the required competence, authority, and engagement.

\section{Key actors}

As none of the assessment processes was formalized or organizationally integrated the process progression was highly dependent on single individuals' ability to define tasks and activities and access organizational structures themselves when needed. Therefore, individuals that possessed information, competence, or authority that was critical to the process continuation became key actors.

These key actors were found both in formalized assessor roles as the feedback provider, in unof- 
ficial roles as the champion, and roles associated with the formal structures of the organization as senior managers. The underlying structural causes for who became a key actor differed with the single situation and task, sometimes related to the structures of an individual actor and sometimes related to the boundary between internal and external structures making information or resources more or less inaccessible to the participants. Despite that, the result was the same, turning single key actors into gatekeepers upon whom process participants and potential stakeholders became dependent in accessing support, critical information about, for instance, the purpose, the assessed area, what had been done, and what needed to be done.

The intention behind the IMSA design that only gave feedback providers access to the group result, was to create a situation where the feedback provider is "forced" to gather the group in joint feedback meetings. It was intended to promote integration and increased learning compared with an alternative situation where each assessor would be given access to the results individually. However, this also made key actors out of the feedback providers as they were the only ones who had access to assessment results on an accumulated group-level.

\section{Negative gatekeepers}

The process continuation became highly dependent upon the key actors' competence and will to give access to critical information, support, or authority, sometimes hindering the continuation within the process (tasks, actors, support) and other times hindering the process from interconnecting with the rest of the organization (information, authority, support). Tasks undertaken were only weakly and arbitrarily interlinked to each other. No structure or routine that merged the tasks into a recognizable pattern of interlinked actions had been identified in any of the projects. These key actors, several times throughout the project, became negative gatekeepers as they had exclusive "ownership" to a specific task or part of the process that hindered the process progression when not undertaken or when others were not given access.

The feedback provider in $\mathrm{C} 1$ is an example of a key actor that became a negative gatekeeper even though he had the will and intention to inform and invite the assessment group to an analysis discussion. He struggled with what seemed to be a weak confidence in his role as a feedback provider, feeling a need to present something more than just the results but did not know how to do that. This was reflected upon at several shared workshops with the other feedback providers. At one of these workshops, one of the feedback providers from project A tried to convince him that it did not have to be so complicated. His experience was that it was enough to share the results provided by the IMSA. He meant that saying nothing more than "this is the result from last week, what do you think it means" had been enough to provide a basis for a good discussion. Despite this, the feedback provider in project $\mathrm{C} 1$ repeatedly addressed the issue of not knowing "how to interpret the results and what to do" when sharing the results. Not feeling confident in what to do, he refrained from sharing the results and we could see how his individual structures became a hindrance that eventually stopped the process.

\subsection{Making people part of the process}

Even though actors were assigned roles in the process as assessors, sponsor, or feedback provider there was no formalized structure that defined how people should take part or be made part of 
the process other than in the assessment phase. In three of the five projects there existed no structural support for interaction between people, between people being part of the process, or with people in the rest of the organization. The support for interaction was highly delimited in the other two projects as well. The only structured interaction support identified were the feedback meetings in projects A and B1 and the workshops arranged by the researchers where the feedback provider and one assessor from each project met and discussed the project.

\section{Fragmented participation}

For various reasons participants came and went during the entire time data was collected partly because different competences and roles were required at different parts of the assessment process or to support different tasks because of unplanned reasons such as re-organizations and redundancies, and planned reasons like job change and parental leaves. Only in project A did two single individuals take part throughout the entire project. No structured routine was developed to ensure that the single individual was actively made part of the process as a whole. When someone left the project, there was no routine that ensured information was documented or passed on, and the knowledge held by that individual left the project with him/ her. Similarly, no routine existed that supported the introduction of new participants to the project; instead, this aspect critically depended on single individuals to take active part in the process by searching or providing required information or support.

"... the commitment disappeared in the staff turnover and our current manager hardly knows what this is," (Feedback provider C2).

During the first year of the study, fragmented participation was, to a great extent, an effect of the fact that all three organizations were struggling with major re-organizations. Even before the assessment started, company B was hit by threats of major redundancies, and the assessment start was postponed while waiting for the final outcome. Meanwhile, the other projects started their assessments and company B re-entered the project after approximately three months. In total, 12 individuals participated in the pre-assessment phase, out of which seven left their projects before the assessment phase started.

"This decision, to participate in the research project, has been taken by people who are no longer with the organization," (Feedback provider, project C2).

In Company B two project groups that were assigned to participate as assessment groups dissolved as their project was indefinitely halted. At short notice, five new participants were assigned to take part in the project. Assessment groups and roles were not yet set.

"I found out about this yesterday... or, I was told to join yesterday," (Feedback provider, project B1).

Only one of these five new participants from company B remained in the project and had a continuous participation. Except for the sponsor, none of the participants from the pre-assessment phase was still part of the project when the assessments started, leaving them with an assessment group where no one within the group's internal structures had knowledge about the purpose of the project, leading to frustration as even the feedback providers that were very engaged in the project and interested in the assessed area (even considering it of critical importance) did not know what to do with the assessment results nor how to handle them. 
"What are we supposed to do with it? What should we change?" (Feedback provider B1).

Only in project A did two single individuals take part throughout the entire project; both were highly engaged feedback providers with prior experience and knowledge about the IMSA and the assessed area. One was also a senior manager with a formal position that gave him access to both the internal and external structures of the assessment group, which all together provided the competence and authority needed throughout all three assessment phases.

"I think my position in the organization is at quite a good level to be able to influence the organization. I am far enough down in the organization to have a feeling for daily activities as I am high enough to get some form of mandate," (Feedback provider 1, project A).

The situation was very different in both company B and C where no single individual represented the entire spectrum of competence or position required to undertake all three assessment phases. Senior management was part of the most initial discussions on whether they should engage in the project or not but was not made active part of the every-day structures of the project. Once the companies had committed themselves to the project, existing groups of suitable size were appointed to participate as assessment groups. Middle managers of these groups were given the roles of feedback providers and were from that point on responsible for the projects. About halfway into the project the $\mathrm{C} 1$ and $\mathrm{C} 2$ projects got a new sponsor who took a more active part in the projects. Two years into the project he initiated a series of meetings where goals, purpose, and methods to reach them was again discussed. The purpose of these meetings was to give the project a re-start. The meetings had a strong pre-assessment character and involved people that represented different internal structures: feedback providers, researchers, upper management, and a manager from human resources. However, whether the sponsor continued to have an active engagement in activities of assessment and post-assessment is unknown as this was at the end of the data collection.

People were primarily made part of the project through their assigned roles in the project and only as an exception were people without an explicit project role made an active part of the process. One example was CC-Solution that invited managers from human resources to take part in goal formulation and meetings to discuss utilization challenges. In project A people from the entire organization were made more indirect part of the process through written information about the project.

The main way that people were made part of the process was through the weekly assessments and the automatically generated feedback on assessments that were sent to all assessors by the IMSA. For three of the assessment projects (B2, C1, and C2) this was the only way that people were routinely made part of the process, meaning that they only took part through their individual undertaking of the assessment task without any recurrent interaction with other people related to the IMSA. These gave the IMSA a primary and potential possibility to have an effect on the individual structures of the participating people and only a potential secondary effect on the internal group structures of these people.

In the two assessment groups that met on a regular basis to discuss and analyze the group level results, people were made part of the process due to their roles as assessors and on the initiative of the feedback providers of their groups. All interactions were undertaken within 
internal structures of established groups with a potential effect on internal group structures and structures of individual people.

\subsection{Affecting how the process was undertaken}

As both people's integration in the process and the process integration in its organizational context to a large extent were undefined and unformalized, the undertaking of the process was to a high degree dependent upon single individuals and groups of individuals. The characteristics of the single participants and groups of individuals (such as knowledge, ability, position, interest, commitment, and will to take part in the process) had a major impact on how the process was undertaken. As a consequence, the processes were undertaken in an arbitrary way due to the participating individuals' will and ability to access and utilize the required structures, information, competences, and resources that were a prerequisite for their undertaking. In turn, this led to an undertaking where the people in the process, to a large extent, participated in a form of process isolation with little interaction between groups of different internal structures. This excluded people from getting and sharing information, and limited how the task results and the process progression were made available. It also affected how information was accumulated both within the assessment process and in its organizational context.

This resulted in five discontinuous and fragmented processes where continuation in tasks, interaction, support, and activities were held together over time only by single individuals.

\section{Discussions}

At first glance, the empirical results indicate that the successful use of an IMSA is dependent on strong individuals who see the big picture, bridging the discontinuities and avoiding the pitfalls of the pre and post-assessment phases (Svensson \& Klefsjö, 2006; Karlsson, 2015), which prior research has shown cause problems (Chiesa et al., 1996; Nilssonet al., 2010). On the contrary, the empirical results could be seen as an illustration of the shortcomings in the undertaking of an IMSA as a process (Langley et al., 2013). These strong individuals that were taking a very personal responsibility for the process could instead be seen as an effect of the major challenges in defining the IMSA as a process where discontinuities appeared as a symptom of an inadequate formalization (Feldman \& Pentland, 2003; Ellström, 2010) of the process in relation to the internal and external structures as well as structures of individual actors (Backström, 2018). When the contextual prerequisites provided by these structures were not acknowledged (Carayannis \& Provance, 2008) the process fragmented and the purpose and progression could not hold together and evolve in an emergent way (Marion, 1999). The undertaking of the IMSA then became dependent upon single individuals acting as bearers of required knowledge and structural access (Anderson \& Krathwohl, 2001), providing them with a power over the process that makes them become a necessity. The individuals who stepped forward and carried on the work prevented the process from a total fragmentation but also hindered interaction (Prigogine, 1997), which confirmed prior research (e.g., Panizzolo et al., 2010 and Biazzo \& Bernardi, 2003).

However, when taking on a process perspective, focus is shifted from single elements towards the 
structural interconnection between different processes (Langley et al., 2013), not as something that needs to be deconstructed into simpler pieces of "what" in order to become more manageable, but rather the opposite, as providing a base for a higher order of emergence that is greater than the sum of its single parts (Marion, 1999). With this focal shift comes a recognition of complexity that implies that context and competence are not only factors that need to be matched and considered to enable a successful utilization of the IMSA; these are rather to be considered interdependent constituents of the process in itself.

Further, with this focal shift comes recognition of complexity that implies that all constituents are of secondary importance, that no single event in the IMSA-process (Samuelsson \& Nilsson, 2002; Karlsson, 2015) is more important than the process in its entirety, consisting of the interdependent connection between its constituents (Marion, 1999; Feldman \& Pentland, 2003; Langley et al., 2013). This means that the assessors' knowledge or key actors' willingness to give access to support is of equal importance as the validity of the indicators. However, as we can see from the empirical evidence, this is only true as long as no single constituent such as a task, activity, or actor is disrupting the continuity of the process by breaking the structures of interconnections that enable the continuous information transfer that in itself constitutes the process (Marion, 1999; Langley et al., 2013). The discontinuities in activities, interaction, and support that were detected made clear how single events and actors such as a negative gatekeeper could be decisive under certain temporal conditions (Langley et al., 2013). Even something as insignificant, from an innovation management perspective, as the self-confidence of one single individual, became crucial in a specific contextual setting, having the power to compromise the progression of the IMSA process and thereby hindering a desired result to emerge (Marion, 1999). Or should we see this as an indication that the IMSA should not be considered as one process but instead consisting of several sub-processes that need to be addressed to be able to undertake the whole assessment process in an effective way?

The very process can, in itself, be seen as the actual interconnection between intention and results, the current situation, its past, and the future (Feldman \& Pentland 2003, Ellström 2010). When the process perspective is lacking in the undertaking of the process, we can see how the process fragments into a discontinuous set of participants and tasks that do not hold together on their own. We lose the dynamics that can only occur in the interaction (Prigogine, 1997) between the process actors that over time binds different organizational structures together around the area assessed. The power of the process is lost. We do not get the intended development of internal structures that could include and link more actors and tasks to the subject at hand, allowing the innovative climate to emerge over time. Instead, a discontinuous actor-participation make the process bounce between temporarily open and closed organizational structures, structures that fluctuate, opening up as internal structures to then become non-accessible external structures depending on who at the moment is taking active part in the process (Backström, 2018). As a consequence, some of the structures that need to develop to increase our innovativeness become unattainable; interactions become limited, fewer participants can contribute to the development, and systemic learning is jeopardized (Marion, 1999).

A well-functioning work process provides participants with an explicit and/or implicit (Ellström 2010) formulated how (Langley et al. 2013), connecting the assessment tasks with the participants who undertake them and allowing single participants or single activities to form a whole 
even if they constitute only a fraction of the entire stock of activities or participants (Marion 1999). Instead, the process becomes dependent on single individuals' will and ability to value, plan, and coordinate the tasks, activities and the participants that need to be part of the assessment work in every specific situation (Langley et al. 2013), driving the progression to become highly demanding for a few (Andersson \& Kratwhol, 2001) and losing flexibility, which makes the process more vulnerable to external changes. At its best, the work toward the desired goal of building more innovative structures that involves more people becomes costly and less effective and at its worst, is never attained. (Marion 1999).

\subsection{Conclusion and future research}

Aiming for a better understanding of the challenges related to the undertaking and utilization of an IMSA, this study focused on how people were made part of the IMSA process and how the IMSA process was integrated in its organizational context. Based the analysis, it can be concluded that how people are made part of the process and how the process is integrated in its organizational context affects how the actors, activities, and tasks can merge into a coherent process that can drive change. This is further described through three main conclusions from the analysis discussed below.

First, the dynamics of both the IMSA process and its contextual setting comes with a metalevel challenge related to how people can be made part of the process and how the process can be integrated in its organizational context. This is a meta-level challenge of understanding the issues of undertaking the process so that the process can be dynamically adjusted to enable the process to stay on track, even though prerequisites are constantly changing. Taking a metalevel perspective on the process requires a combined awareness of the area assessed, the process of undertaking and utilizing the IMSA, and understanding how both of these are related and affected by its organizational setting.

Second, it can be concluded that it is not only how the process is integrated in its organizational context that affects how and if a purposeful use is enabled, but rather a question of how the process integration in its organizational context binds to the structures it is intended to change. A formal or informal integration that gives the people who are part of the process access to the targeted structures over the entire process increases the chances for a purposeful use of the IMSA. This shows that there is an interdependency between how the process is integrated in its organizational context and how the people are made part of the process, together affecting how a purposeful use of the IMSA is or is not enabled.

Third, it is suggested that the undertaking of the IMSA process could be considered a dual process consisting of two closely interlinked and interdependent processes. These processes include an implementation process concerning the practical undertaking of the IMSA and a support process concerning the meta-level requirements to be addressed in order to avoid fragmentation and an arbitrary dependency on single individuals that are part of the process. 


\subsection{Practical implication}

When undertaking an IMSA, it is suggested that the undertaking should be considered a dual process. One process, the implementation process, concerns the actual and practical undertaking of the IMSA. This is the process where actors undertake tasks and activities to enable the desired improvement to emerge. While the other process, the support process, concerns the planning, enabling, and dynamic adjusting of the conditions to meet changes in internal and external prerequisites. The two closely intertwined processes are highly interdependent upon each other and both processes need to be considered and managed.

How people are made part of both these processes, and how they are integrated in their organizational context, will affect how a purposeful use will be enabled to emerge. A practical implication of this research is that the competences that can be made available and accessible throughout the process can be considered a strong indicator of what achievements can be expected from the undertaking of the IMSA. When undertaking the implementation process, focus needs to be on that people with the required competences in terms of both knowledge and authority are made part of the process, either as active participants or as support providers. Further, it is essential to ensure that the process is made part of its organizational context in such a way that it provides the required accessibility throughout the entire process in terms of support, structures, and interaction.

When undertaking the support process, focus should instead to be on the meta-level, ensuring that the purpose fits with the requirements of the process and the competences available. The parts of the process that are not provided formalize needs to be identified so that these can be designed, and the undertaking can be prepared. The process needs to be monitored over time to identify changes in conditions that will require a redesign of the process and support. Focus of the support process is on providing a setting that enables a continuous process that allows situational leadership and permits actions to emerge that influence established structures and routines. Enabling peoples' participation in the process includes, assuring they understand who should be involved in what part of the process, empowering the people, and adequately supporting them in terms of time, knowledge, information, and structural accessibility, among other factors.

\subsection{Limitations and future research}

The major limitations of this study are related to the difficulties in capturing the content of a process and the challenges related to case selection. First, it is challenging to observe a process as it is not a visible entity that can be observed in itself due to its content, but it must instead be observed through how the behaviors develop over time. Therefore, observing how people are made part of the process and how the process is integrated in its organizational context requires a data collection that allows a close interaction with the people that are populating the process and its context. This helps identify not only what is said, but also the behavior and what is actually done. The complexity of both the process and its contextual setting make it impossible to observe a process in its entirety, and there is always a risk that the data collected at a specific moment in time, with specific participants, does not give a strong representation of the process. 
A longitudinal study like this study is a way of increasing the quality of the study as it focuses on the abstraction of how relations, interactions, changes, form patterns over time. An ethnographic approach, with more time on site, could be a way to improve the quality of future studies.

When working with case studies, the quality of the empirical results is not only dependent upon the way information is collected, but also, it is highly dependent upon the selection of the cases. Even though the selected cases gave adequate access to data, these cases did not provide the desired data width as none undertook the entire IMSA process without being dependent on single individuals. However, the cases did provide valuable insights that probably could not have been captured in a process with less problems and complications. Including strong, successful cases in future studies is however desirable to provide a greater variety to explore.

To advance the IMSA research, it is suggested that future studies take a systemic perspective on the assessment situation that would allow the acknowledgement of the bigger picture of use and application. Even when researching a limited part of the process, such as a development of assessment indicators, it is suggested that these are considered from the perspective of use and application by discussing them in relation to purpose, contextual setting, and competence requirements.

Knowledge from other fields of research could also be used to accelerate IMSA research such as the field of education and learning that concerns knowledge, competence, and structural support for learning. One example is the research on self-regulated learning that addresses selfassessment issues similar to those within the field of innovation management. One example is research by Kostons et al. (2012) that shows that training students' self-assessment and task-selection skills can significantly increase the amount of knowledge they can gain from selfregulated learning where they choose their own learning tasks. This might provide an interesting research opportunity within the context of innovation management.

\section{References}

Adams, R., Bessant, J. \& Phelps, R. (2006). Innovation management measurement: A review. International Journal of Management Reviews, 8 (1), 21-47.

Alegre, J., Lapiedra, R. \& Chiva, R. (2006). A measurement scale for product innovation performance. European Journal of Innovation Management, 9 (4), 333-346.

Anderson, L. W., \& Krathwohl, D. R. (Eds.). (2001). A taxonomy for learning, teaching, and assessing: A revision of Bloom's taxonomy of educational objectives. New York: Longman.

Backström, T. (2018). Understanding and facilitating creative group processes: The GroPro model. Retrieved from https://www.researchgate.net/publication/329416354_Understanding_ and_Facilitating_Creative_Group_Processes_The_GroPro_Model doi:10.13140/RG.2.2.31773.15847

Backström T, Döös M \& Wilhelmson L. (2006). Chefen som regissör - ledarskap och medarbetarskapets självorganiserande processer [The supervisor as a director - the self-organised processes of leadership and co-workership]. In Swedish). In Ledarskap för fria medarbetare [Leadership for free coworkers]. von Otter C (Ed). Stockholm. Arbetslivsinstitutet. 
Berger, L. P. \& Luckman, T. (1979). Kunskaps sociologi. Hur individen uppfattar och formar sin sociala verklighet. $2^{\text {nd }}$ edition (first Swedish), Falun, Sweden. Wahlström och Widstrand.

Biazzo, A. \& Bernardi, G. (2003). Organizational sef-assessment options. A classification and a conceptional map for SMEs. International Journal of Quality $\& 3$ Reliability Management, 20(8), 881-900.

Biloslavo, R. (2005). Use of the knowledge management framework as a tool for innovation capability audit. International Journal of Innovation and Learning, 2 (4), 402-424.

Birchall, D., Chanaron, J-J., Tovstiga, G. \& Hillenbrand, C. (2011). Innovation performance measurement: current practices, issues and management challenges. International Journal of Technology Management, 56 (1), 1-20.

Björkdahl, J. \& Börjesson, S. (2012). Assessing firm capabilities for innovation. International Journal of Knowledge Management Studies, 5 (1/2), 171-184.

Carayannis, E.G. \& Provance, M. (2008). Measuring firm innovativeness: towards a composite innovation index built on firm innovative posture, propensity and performance attributes. International Journal of Innovation and Regional Development, 1 (1), 90-107.

Chiesa, V., Coughlan, P. \& Voss, C. A. (1996). Development of a technical innovation audit. The Journal of Product Innovation Management, 13(2) 105-136.

Coombs, R., McMeekin, A. \& Pybus, R. (1998). Toward the Development of Benchmarking Tools of R\&D Project Management. $R$ \& D Management, 28 (3), 175-186.

Cormican, K. \& O'Sullivan, D. (2004). Auditing best practice for effective product innovation management. Technovation, $24(10), 819-829$.

Cropley, H. D., Cropley, J. A., Chiera, A. B \& Kaufman, C. J. (2013). Diagnosing organizational innovation: Measuring the capacity for innovation. Creativity Research Journal, 25 (4), 388396.

Dewangan, V. \& Godse, M. (2014). Towards a holistic enterprise innovation performance measurement system. Technovation, 34(9), 536-545.

Dobni, C Brooke. (2008) Measuring Innovation Culture in Organizations. European journal of innovation management, 11(4), 539-559.

Dobni, C.B. \& Klassen, M. (2018). Linking innovation measurement to an implementation framework: A case study of a financial services organization at the front end of innovation. Journal of Innovation Management, 6 (1), 80-110.

Ekvall, G. (1996). Organizational climate for creativity and innovation. European Journal of Work and Organizational Psychology, 5(1), 105-123.

Ellström, P-E. (2010). Practice-based innovation: a learning perspective. Journal of Workplace Learning, 22(1), 27-40.

Feldman, M. S. \& Pentland, B. T. (2003). Reconceptualizing organizational routines as a source of flexibility and change. Administrative Science Quarterly, 48(1), 94-118.

Hallgren, W. E. (2009). How to use an innovation audit as a learning tool: A case study of 
enhancing high-involvement innovation. Creativity and Innovation Management, 18 (1), 4858 .

Janssen, S., Moeller, K. \& Schlaefke, M. (2011). Using performance measures conceptually in innovation control. Journal of Management Control, 22(1), 107-128.

Karlsson, H. (2015). Innovation auditing, the audit and the auditor. Lic. Mälardalen University. Västerås: Mälardalen University Press.

Kerssens-Van Drongelen, I. C. \& Biderbeek, J. (1999). RnD performance measurement: more than choosing a set of metrics. RnD Management, 29(1), 35-46.

Kostons, D., Van Gog, T. \& Paas, F. (2012). Training self-assessment and task-selection skills: A cognitive approach to improving self-regulated learning. Learning and Instruction, 22(2), 121-132.

Langley, A., Smallman, C., Tsoukas, H. \& Van De Ven, A. (2013). Process studies of change in organization and management: unveiling temporality, activity, and flow. Academy of Management Journal, 56(1), 1-13.

Marion, R. (1999). The edge of organization. USA, SAGE Publications, Inc.

Maxwell, J.A. (2013). Qualitative research design: an interactive approach. Thousand Oaks, CA, USA. SAGE Publications, Inc.

Merriam, S. \& Tisdell, E. (2016). Qualitative research. A guide to design and implementation. USA, John Wiley \& Sons Inc.

Moultrie, J. P., Clarkson, J. \& Probert, D. (2007). Development of a design audit tool for SMEs. Journal of Product Innovation Management, 24 (3), 335-36

Moynihan, D. P. (2009). Through a glass, darkly. Public Performance 8 Management Review, $34(4), 592-603$

Nilsson, F., Regnell, B., Larsson, T. \& Ritzén, S. (2010). Measuring for innovation - a guide for innovative teams. Applied Innovation Management, (2), 2-29.

Ohlsson, J. \& Johansson, P. (2010). Interactive research as a strategy for practice-based learning: Designing competence development and professional growth in local school practice. In: Billett, S. (ed.) Learning through practice. Models, traditions, orientations and approaches. London, New York: Springer international.

Panizzolo, R., Biazzo, S. \& Garengo, P. (2010). New product development assessment: towards a normative-contingent audit. Benchmarking: An International Journal, 17(2), 173-194.

Peterson, R. A. (2000). Constructing effective questionaries. Thousand Oaks, California, USA, Sage Publications, Inc.

Pettigrew, Andrew M, Woodman, Richard W, and Cameron, Kim S. (2001). Studying Organizational Change and Development: Challenges for Future Research. The Academy of Management journal, $44(4), 697-713$.

Prigogine, I. (1997). The end of certainty - Time chaos and the new laws of nature. New York, USA, Free Press. 
Radnor, Z. \& Noke, H. (2002). Innovation compass: A self-audit tool for the new product development process. Creativity and Innovation Management, 11(2), 122-132.

Rossman, G. B. \& Rallis, S. F. (1998). Learning in the field. An introduction to qualitative research. USA, SAGE Publications, Inc.

Samuelsson, P. \& Nilsson, L-E. (2002). Self-assessment practices in large organizations Experiences from using the EFQM excellence model. International Journal of Quality 85 Reliability Management, $19(1), 10-23$.

Saunders, M., Lewis, P. \& Thornhill, A. (2012). Research methods for business students. Essex, England, Prentice Hall.

Svensson, L., Ellström, P-E. \& Brulin, G. (2007). Introduction - on interactive research. International Journal of Action Research, 3(3), 233-249.

Svensson, M., \& Klefsjö, B. (2006). TQM-based self-assessment in the education sector: Experiences from a Swedish upper secondary school project. Quality Assurance in Education, 4(14), 299-323.

Tidd, J. \& Bessant. J. (2013). Manageing innovation. integrating technological, market and organizational change. West Sussex, England, John Wiley \& Sons Ltd.

Van De Ven, A. H. (1992). Suggestions for studying strategy processes: A research note. Strategic Management Journal, 13(S1), 161-188.

Yang, J.B., Dale, B.G. \& Siow, C.H.R. (2001). Self-assessment of excellence: An application of the evidential reasoning approach. International Journal of Production Research, 39(16), 3789-3812.

Yin, K.R. (2009). Case study research. Thousand Oaks, CA, USA, SAGE Inc. 


\section{Biographies}

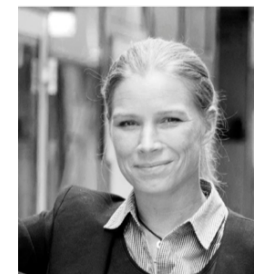

Helena Blackbright. Helena Blackbright received two B.Sc. degrees in 2005, one in innovation technology and one in business economy from Mälardalen University, Sweden. In 2015 she received the Ph.Lic. degree in innovation management, also from Mälardalen University. She has over 20 years of industrial and academic experience from the field of innovation and innovation management. Since 2016 she shares her time between $\mathrm{PhD}$ studies in innovation management at Mälardalen University and as a project manager at Automation Region, Västerås, Sweden. Her research focus lies in the field of conditions for maintained and increased organizational innovativeness in complex adaptive systems and she is currently writing on the manuscript of her PhD thesis, Exploring Purposeful use of Innovation Management Self-Assessments. Ph.Lic. Blackbright has over the last years developed a great interest in human centred AI and AIs impact on innovation management and is one of the co-founders of the Swedish based initiative addAI.org that focuses on exploring the impact of smart algorithms and AI on society. She is also the initiator of the ISPIM Special Interest Group, AI \& Innovation Management, exploring the encounter of AI and innovation management. 